\title{
A Study on Teaching Model of Integrating Intercultural Competence with English Intensive Reading
}

\author{
Xun $\mathrm{Bu}$ \\ Shanghai Normal University Tianhua College \\ Shanghai, China \\ elynxun@163.com
}

\begin{abstract}
In the context of weak cross-cultural awareness and low cultural competence of English majors, this paper mainly explores how to integrate the cultivation of cross-cultural competence into the intensive reading course, so as to promote students' language and cross-cultural ability. Based on Moran's cultural learning mode of Cultural Knowings and Byram's explicit culture skills of discovery, contrast and analysis, this paper, given English major juniors' cognitive and language level in private college, proposes a comprehensive blended teaching mode of before- during-after class, which digs deep into the text analysis and simultaneously the cultural connotations between the lines, thus enabling students to acquire macro cultural knowledge through micro language points. Hopefully, this paper can offer new approaches to IC-language teaching.
\end{abstract}

Keywords-Intensive English reading; Intercultural competence; IC-language teaching

\section{INTRODUCTION}

Currently, economic globalization and cultural diversity have greatly increased the demand for high-quality talents with inter-cultural competence, and foreign language education has become an important channel to cultivate inter-cultural communication. In recent years, the cultivation of college students' intercultural competence has become a common concern in language education both at home and abroad. The National Medium and Long-term Education Reform and Development Plan (2010-2020) also outlines solid basic language skills, inter-cultural communication, broad international vision and patriotism as basic qualities of English majors, and emphasizes the effective integration of language skills, application of language with cultural knowledge and communication skills. However, many English majors show rather low inter-cultural awareness, whose cultural knowledge is limited to only superficial cultural phenomenon such as customs and habits, important festivals. Meanwhile, they display little knowledge in deep-rooted culture, such as communication rules, ways of thinking, system of values. Besides, their expression, both written and oral, and thinking mode are strongly influenced by their mother tongue [1].

\section{LITERATURE REVIEW}

At present, the commonality of foreign inter-cultural studies in language education is the lack of attention to language teaching procedure and teaching effect. Various modes lay stress on the cultivation of inter-cultural competence, while ignoring specific ideas and practices of combining language and culture [2]. The combination of language skills and inter-cultural skills is not systematic and fragmented, and there are few classroom teaching practices available that can organically integrate the above two. Although intercultural communication was listed as one of the main contents of college English course in College English Teaching Requirements in 2007, it did not specify what to teach, how to teach and how to implement it [3]. Some schools have separate courses on intercultural communication, but pay insufficient attention to language learning.

Chang xiaomei and Zhao yushan (2012) conducted action research on how to systematically integrate language teaching with intercultural competence. According to the characteristics of intercultural teaching and the principles to be followed, teaching activities center around the topic of each unit. According to the "Cultural Knowings" proposed by Moran [4], the teaching activities are divided into four stages: (1) describe Cultural information; (2) analyze cases; (3) participate in communication activities; (4) reflect on cultural differences. The whole teaching process adopts interactive teaching method, that is, students learn classroom materials in an interactive way, including listening and reading cultural resources, participating in case discussions, carrying out communicative activities and thinking about cultural differences. Regarding how to combine IC competence with the specific language skills, and their relationship, Yang hua and Li liwen conducted two rounds of action research, which was initiated by the cultivation of intercultural competence and aimed to enhance students' acquisition of inter-cultural knowledge, and ultimately promote their inter-cultural attitudes such as open-mindedness and tolerance. Researchers incorporated the language objectives and inter-cultural objectives in the teaching events of IC language teaching, and achieved a highly operational teaching model with integrated explicit inter-cultural skills "discovery", "comparison" and "analysis" by designing "output-oriented" inter-cultural tasks. This model consists of four parts, namely, goal setting, task setting, task implementation and evaluation and reflection.

Although there are more and more domestic scholars who shift their focus to integration of English and inter-cultural education, and put forward specific teaching methods [5], 
these studies mainly aim at non-English majors in public universities. Little research is available regarding the course of English intensive reading and research taking English majors in private colleges as subjects are even less.

\section{IC LANGUAGE TEACHING}

Based on previous inter-cultural teaching theories, it can be seen that despite different expressions, the major elements are basically the same.

Given the cognitive level and language proficiency of junior English majors in private colleges, the author systematically incorporates basic elements of intercultural language teaching in the teaching procedure of intensive reading course. Specifically, before class, the teacher provides diverse cultural input online, thus enabling students to discover different cultural phenomena when preparing texts and cultivating their autonomous learning. During class the teacher focuses on texts, analyzes language, motivates students to think by means of heuristic questions, makes inter-cultural communication happen by design various tasks and encourages students to compare different cultures, thus enhancing students' collaborative learning. After class, students are encouraged to expand their reading, search for materials, explain and analyze the roots of different cultural phenomena, and conduct deep learning.

\section{A. Before Class}

Take My Wood, unit 11 of Integrated English Book 6, as an example. The author of this article is British writer E M Forster, who discusses the psychological effects of property on human's character. The text features a large number of words, sentence patterns and biblical allusions with rich cultural connotations, which serves as perfect material for inter-cultural language teaching. Blended approach of online and classroom teaching was adopted: the teacher uploaded diverse cultural learning materials to the chapters and resource section of the online course before class, including micro lectures, audio and video clips, classic reading and so on. For example, the teacher selected an interview program in which the three guest speakers expressed their views on property, so that students could hear different voices, accept diverse views, and obtain an open and tolerant cultural attitude. Meanwhile, the teacher also designed blank filling exercises to provide language input and reserve such as vocabulary, so as to prepare students for the subsequent output-driven exercise. Besides, the teacher chose a TED lecture on minimalism, and asked students to summarize the speakers' views and answer the question: If you were the speaker, with an annual salary up to a million, would you give up everything and make the same choice? In this way, the students were put in the context and encouraged to think deeply. In addition, given the difficult cultural point of rhetorical technique - allusion, the teacher recorded a micro-lecture for students to study in advance in order to improve class efficiency. At the same time, teachers also uploaded the preview assignments and learning chart to online course for students' autonomous learning, so as to facilitate students purposeful and targeted learning. Otherwise the so-called preview means nothing but reading the text and checking up new words. Therefore, students, equipped with knowledge and questions, come to class and pick up their roles more quickly, which enables them to have deeper and more efficient interaction with teachers.

\section{B. During Class}

During class, the teacher first conducts textual analysis, invites students to report and present their individualized Autonomous Learning Chart (ALC), and answers questions raised by students. The ALC adopts the bottom-up mode, including vocabulary, sentence patterns, rhetorical device, paragraph understanding and theme exploration. At the lexical level, students spotted kingdom of Heaven, robe of God, bath in Jordan, bishop, pulpit, Son of Man, sinister trinity and other words with rich cultural connotations, and explained them based on their preparation. Regarding syntactic level, students raised the following questions: Why does the author say "A cheque to the author was the result." instead of "I earned some money."? Why would others participate in the author's shame as he bought the wood? Why are there so many short sentences in the fourth paragraph? What is his point? What rhetoric devices is employed regarding the sentence "The Furniture requires dusting, dusters require servants, and servants require insurance stamps.”? Instead of giving direct answers, the teacher mainly guided the students and supplemented some important cultural points by Socratic questions: Is there an equivalent of asceticism in Chinese culture? How to understand Dante's paradox of "Possession is one with loss."? How to interpret the quote of Shakespeare's sonnet 129 in paragraph 5? What is the symbolic meaning of "blackberries" in paragraph 6? The teacher will keep asking questions to arouse students' association with their own experience and encourage them to render the issue from a different perspective. As to the second effect proposed by the author, the teacher asked, "Do you agree with the author? Do you have similar experience? Are you satisfied with what you have? Do you need something else to match the fancy dress or shoes?" which triggered a heated discussion, caused empathy among students, and echoed the author's view "endlessly avaricious", to which students displayed strong approval.

As to the three biblical allusions in text, the teacher set up the first cultural communication task - one group served as cultural commentators, referred to the pictures and key words, illustrated the cultural connotation of allusions, and discussed with other students how the allusions contribute to the author's point. Through the presentation, the students in this group internalized knowledge, and the other students understood the author's point better: Property makes people heavy, greedy and selfish. The second cultural communication task was a presentation of view on property reflected in Chinese allusions and a comparative analysis with the text. Students cited the classics and famous quotes like "Unjust fortune and power mean nothing to me", and pointed out that Chinese men of letters "regard money as dirt". Some quoted a passage from The Scholars: The lord stuck out two fingers before death to show his concern about the oil burnt, "You are worried about the two bulrushes burnt in that lamp. I am now picking out a stalk. ", vividly showing the image of a miser in feudal society, which is similar to the extremely selfish neighbor described in paragraph 7. Other students spotted an episode in Chinese fairy tale Feng Shen Yan Yi: after King Zhou in Shang Dynasty who was originally thrifty and industrious received a pair of ivory 
chopsticks, he then wanted a golden bowl to match the chopsticks, a table to match his bowl, and even a matching palace and status, whose endless avarice cost him the whole country. This Chinese allusion echoes the biblical one in paragraph 4: King Ahab was so greedy that he wanted Naboth's vineyard and finally caused Naboth's death. The cultural comparison enables students to understand that despite different cultural backgrounds, the deep-rooted humanity and values reflected are surprisingly similar. Intercultural language teaching does not simply teach students cultural knowledge in class, but trains students' comprehensive ability to understand the uniqueness and universality of culture by emphasizing empathy of culture and deep understanding of the universal concept of culture [4]. The third culture communication task is case study. Students compared China's November 11th shopping spree and American Black Friday shopping craze, discussed whether possessions make people happy and analyzed the cultural background and thinking mode behind the phenomenon. Schmidt [6] believes that through the comparison and analysis of important events in different cultural backgrounds, the understanding of target culture and native culture can be strengthened. Case study enables students to identify cultural differences according to their own feelings, reflect on their own culture, and realize the transition from "ethnocentrism" to "ethnorelativism" [1]. The last cultural communication task is poster-designing, which aims at advocating minimalist lifestyle and cultural values on campus. Many students decided to try a minimalist life, get rid of unnecessary things, simplify their social circle, deprive themselves of network, so as to reduce the psychological burden, shift their attention to what can bring true content and happiness, such as reading, body-building, etc.

\section{After Class}

After class, the teacher carefully selects classic works, encourages students' further reading and deep thinking, and asks them to make a comparative analysis of Chinese and western cultural phenomena and values mirrored, find out the similarities and differences, and analyze the cultural roots that give rise to the differences. For example, the teacher provided a supplementary reading of Laurie Lee's Appetite and Crowley's of Avarice and designed a worksheet. Students were asked to analyze the similarities and differences between the two articles in terms of author's point, the view on property, conduct a cultural reflection based on the values of Chinese allusions discussed in class, explore the cultural roots, and draw a mind map. For those who are willing to dig deeper, the teacher would assign them with a more challenging task of the academic paper focusing on comparative analysis of culture.

\section{REFLECTION}

Firstly, through this teaching practice, the author thinks that cultivation of inter-cultural competence needs to rely on the language teaching environment. One is the purpose and the other means, and vice versa. The two can be organically integrated, systematically connected and complement each other. When designing teaching, teachers can feed students with a relevant cultural material package according to the theme of the text, dig deep into the hidden cultural connotation through the analysis of micro language points, interpret the cultural causes and thinking mode behind it, and comprehend its decoding process. For example, in the textual analysis, words, sentences and rhetorical devices with rich cultural information are explained in great detail, through which cultural phenomena and background can be understood, thus achieving "macro- micro mutual reference".

Secondly, intercultural language teaching is realized through a closed teaching circle consisting of three indispensable links: before class, during class and after class. Considering the cognitive level and language ability of English majors in private colleges,

Before class, the teacher selects engaging and up-to-date cultural cluster that is closely related to students' life, stimulates students' motivation in learning, and creates the cultural environment which they can consciously immerse themselves into. For example, when dealing with the topic of racial discrimination in unit 1 of Book 5, the teacher chose several episodes from the latest Oscar Winner Green Book, and several paragraphs from the best-seller, Michelle Obama's autobiography Becoming, thus exposing students to the latest first-hand materials. Students were asked to describe the racial discrimination in America according to what they watched and read, and share what they thought. Movies and TV series are the epitome and true portrayal of the daily life of millions of Americans. These video and audio materials enable students to put themselves in others' shoes, understand cultural phenomena, quickly stimulate their experience, and achieve empathy, which is conducive to developing open-mindedness towards cultural communication.

During class, the teacher designs various teaching activities, maximizes students' communicative intention through heuristic questioning and different tasks and simulates communicative scenes, thus promoting collaborative learning and cultivating inter-cultural competence. For example, when explaining western superstitions, the teacher introduced the specific superstitious phenomena and launched a contest on superstition. Besides, one group of students acted as Chinese tour guides to introduce Chinese superstitions to foreign tourists and how to avoid taboos to achieve effective inter-cultural communication. Zhao Haiyan [7] once claimed that with the continuous expansion of China's influence in the world and the need to spread Chinese culture abroad, it is inevitable to cultivate students' two-way inter-cultural awareness. Therefore, teachers should increase the content of Chinese culture in teaching design, promote national culture, and enhance the awareness of cultural equality. When teaching American lifestyle, the topic of unit 6 Book 5, the teacher presented a caricature comparing Chinese and western lifestyles, ask the students to write a play script and role play accordingly. The play was supposed to reveal the cultural conflicts and communication barriers or failures caused by it, and finally make an illustrated cultural manual, listing the practical cultural tips. In this process, students not only observe, describe, analyze and explain communication phenomena but also actively interpret how "ego culture" and "other culture" promote or hinder cultural communication in the context of multi-cultural society [8]. 
After class, the main job is to expand, consolidate, evaluate and apply so as to promote the transfer from language and culture input to output. Meanwhile, the online platform is an effective tool to conduct a formative assessment of students' learning. Teachers should offer supplementary reading, links to related knowledge, encourage students to further explore their cultural interest and the root, stimulate their motivation for deep learning, thus fostering their confidence and sense of achievement.

\section{CONCLUSION}

Firstly, students should be the center in the teaching process to strengthen the interaction between teachers and students and among students. Teachers should simulate cultural scenarios, create relevant contexts and set up various tasks to drive students to conduct inter-cultural communication. In addition, the inter-cultural teaching process should keep pace with the times, adopt blended teaching, take advantage of scientific and technological platforms, upload rich cultural resources to online course, conduct cultural tests, carry out inter-cultural comparative analysis and discussion, encourage peer assessment and review, and give timely and effective feedback from teachers. In fact, the cultivation of students' inter-cultural competence also puts forward newer and higher requirements for teachers' own cultural accomplishment, humanistic vision and inter-cultural knowledge reserve. It is a question worth pondering a whole life for every teacher how to design engaging cultural communication tasks according to the theme of the text and the actual ability of students, and at the same time stimulate their deep thinking about the similarities and differences of cultures.

\section{REFERENCES}

[1] Chang Xiaomei, Zhao Yushan. 2012. Action research on college English teaching to improve students' cross-cultural awareness [J]. Foreign language field, (2): 27-34.in Chinese

[2] Yang Hua, Li Liwen. 2017.Action research on integrating intercultural competence with college English teaching [J].Foreign language and foreign language teaching, (2):9-17.In Chinese

[3] Ge Chunping, Wang Shouren.2016. Intercultural communication competence and college English teaching $[\mathrm{J}]$. Foreign language and foreign language teaching, (2): 79-86.in Chinese

[4] Moran P R. Teaching Culture: Perspectives in Practice [M]. Boston: Heinle \& Heinle, 2001.

[5] Sun Youzhong.2016. Foreign language education and intercultural competency training tian China foreign language $[\mathrm{J}]$. Chinese foreign language, (3): 16-22. In Chinese

[6] Schmidt, P. 1998. The ABC's of cultural understanding and communication [J]. Equity \& Excellence in Education, (2):28-38.

[7] Zhao Haiyan.2013. On the two-way growth of cross-cultural awareness in English education in China. Journal of Chinese education [J], (11):67-69. In Chinese

[8] Scaring, A. 2009. Assessing intercultural capability in learning languages: Some issues and considerations[J]. Language Teaching, (1):67-80. 